\title{
Pierre Limouzin, 2000, La France et ses régions,
} inégalités et mutations

Paris, Armand Colin, 186 p.

Jean-Pierre Husson

\section{OpenEdition}

\section{Journals}

Édition électronique

URL : http://journals.openedition.org/rge/4139

DOI : $10.4000 /$ rge.4139

ISSN : 2108-6478

Éditeur

Association des géographes de l'Est

Édition imprimée

Date de publication : 1 juin 2000

ISSN : 0035-3213

\section{Référence électronique}

Jean-Pierre Husson, "Pierre Limouzin, 2000, La France et ses régions, inégalités et mutations », Revue Géographique de l'Est [En ligne], vol. 40 / 3 | 2000, mis en ligne le 03 août 2013, consulté le 25 septembre 2020. URL : http://journals.openedition.org/rge/4139; DOI : https://doi.org/10.4000/rge. 4139

Ce document a été généré automatiquement le 25 septembre 2020

Tous droits réservés 


\section{Pierre Limouzin, 2000, La France et ses régions, inégalités et mutations}

Paris, Armand Colin, 186 p.

Jean-Pierre Husson

\section{RÉFÉRENCE}

Pierre Limouzin, 2000, La France et ses régions, inégalités et mutations, Paris, Armand

Colin, $186 \mathrm{p}$.

1 En cinq chapitres, l'auteur apporte une intéressante contribution synthétique sur la réalité plurielle d'une France qui évolue à plusieurs vitesses et résiste tant bien que mal au maintien de l'idéal républicain d'égalité pour tous, à toutes les échelles emboîtées du territoire, en prenant compte de l'émergence affirmée d'une économie globale sinon européenne.

2 L'auteur part du constat des inégalités critériées par la richesse, les différentiels de mortalité, de chômage, de délinquance, de pollution, etc, donnant une image retouchée, nuancée d'une France où s'opposent les zones qui gagnent, les territoires sur la défensive, les espaces en retrait mais également l'approche revisitée d'une France inversée.

3 Ensuite, P. Limouzin apporte des rappels concernant l'évolution socio-économique (croissance, désindustrialisation et redéploiement industriel, services, administrations, évolution démographique) sans peut être insister suffisamment sur l'important capital d'innovation et d'inventivité qui anime aujourd'hui les formes encore parfois très juvéniles de la nouvelle économie.

4 P. Limouzin se place à l'échelle des macro-régions (le Grand Ouest), des territoires partageant des éléments de synergie (Alsace et Rhônes-Alpes dynamisés par la donne transfrontalière) ou ayant encore des challenges à dépasser (quart Nord-Est en train de surmonter ses handicaps hérités du passé industriel). 
5 Les scénarios, bifurcations, accélérations, reculs provoquent des disparités inscrites à tous les niveaux d'analyse, dominant des territoires vacuolaires, privilégiant les axes, les zones d'interface, les territoires nodaux mis en réseau. Ainsi se recompose sans cesse une nouvelle géographie de la partition entre les territoires de projets porteurs et les autres. Cette approche difficile, mouvante qui laisse aussi la place à des zones de transition, floues, parfois dans l'expectative est essentielle mais aurait probablement gagné à être illustrée par une cartographie qui descende, par des exemples, à tous les échelons de l'analyse approchée.

6 L'ouvrage se termine par un éclairage sur les nouveaux outils d'aménagement du territoire cadrés par les lois de décentralisation désormais nourries par près de deux décennies d'expérimentation; Les diverses formes territoriales de projets reposant sur l'intercommunalité, le développement local, l'émergence des "pays » sont bien connues de l'auteur qui aurait pu étoffer ce chapitre novateur. Les données expérimentées depuis peu sont, avec l'éclairage des trains de lois récentes - dont la LOADT - un élément fort de refonte des territoires par partenariat consenti autour du soutien de projets partagés.

7 Au total, l'ouvrage de P. Limouzin livre au lecteur des pistes claires en analysant les formes de recomposition des territoires classées dans le souci d'une approche d'intégration à une économie globale.

\section{AUTEURS}

JEAN-PIERRE HUSSON

Université Nancy 2 